\title{
Impact of Different Etiologies of Bronchiectasis on the Pulmonary Function Tests
}

\author{
Agnaldo José Lopes, PhD; Gustavo Bittencourt Camilo, MSc; Sara Lucia Silveira de Menezes, PhD; \\ and Fernando Silva Guimarães, PhD
}

\begin{abstract}
Background: Bronchiectasis develops along the natural course of several respiratory and systemic conditions and induces significant changes in the morphofunctional structure of airways. Our objective was to assess the impact of various causes of bronchiectasis on clinical data, pulmonary function tests, and high-resolution computed tomography (HRCT).
\end{abstract}

Methods: The present report was a cross-sectional study that was conducted with 112 consecutive patients with bronchiectasis, who were allocated to five groups, as follows: sequelae of tuberculosis, history of non-tuberculosis infection, cystic fibrosis (CF), primary ciliary dyskinesia (PCD), and rheumatoid arthritis. All of the participants underwent spirometry, whole-body plethysmography, measurement of the diffusing capacity for carbon monoxide (DLco), and HRCT.

Results: The highest HRCT score was exhibited in patients with CF $(6.03 \pm 1.03)$. The values of forced expiratory volume in I second $\left(\mathrm{FEV}_{1}\right)(52.2 \pm 17.7 \%)$ and DLco $(74.1 \pm 15.2 \%)$ were lower in patients with sequelae of tuberculosis. The increase in the residual volume was more accentuated in the patients with CF (I93.5 $\pm 39.5 \%)$ and PCD (I89 $\pm 36.4 \%)$. By the multivariate analysis, the cause of bronchiectasis, HRCT score, and degree of dyspnea behaved as independent predictors of FEV and DLco.

Conclusion: In individuals with bronchiectasis, the pulmonary function abnormalities are associated with the etiology of the underlying disease.

Keywords: Bronchiectasis; Respiratory function tests; Respiratory mechanics; Tomography

$\mathrm{B}$ and irreversible dilatation of the bronchia due to the destruction of the elastic and muscular components of their walls. ${ }^{1,2}$ That condition represents the final common pathway of several respiratory and systemic diseases. ${ }^{3,4}$ Its incidence exhibits wide variation among different populations, ranging from 3.7/100,000 children in New Zealand to 52/100,000 adults in the United States. ${ }^{2}$ This wide variation might be accounted for by the use of different diagnostic methods and different criteria for patient selection. ${ }^{5,6}$ In a study of patients with bronchiectasis conducted in Hong Kong, Chan et $\mathrm{al}^{7}$ found a prevalence of $19 \%$. In Brazil, Bogossian et $\mathrm{al}^{8}$ assessed 314 individuals with bronchiectasis and found that a high percentage of the cases $(42.7 \%)$ corresponded to sequelae of tuberculosis, while the remainder of the cases $(57.3 \%)$ was due to other causes.

In the past, bronchiectasis was considered an orphan disease; however, following the advent of high-resolution computed tomography (HRCT), the number of cases diagnosed increased worldwide. ${ }^{6-9}$ HRCT is the best available method to establish the presence and distribution of bronchiectasis,

Corresponding Author: Agnaldo José Lopes, PhD; Rua Araguaia; 1266 bloco I/405; Freguesia, Jacarepaguá, 22745-27I, Rio de Janeiro, RJ, BRAZIL; 
with $96 \%$ sensitivity and $93 \%$ specificity. ${ }^{10}$ HRCT is able to assess the structural damage caused by bronchiectasis, including the number of affected bronchopulmonary segments. Interestingly, the severity of bronchiectasis bears correlations with the measures of airway obstruction. $^{2}$

Impaired lung function in patients with bronchiectasis usually leads to an obstructive defect. ${ }^{11,12}$ The mechanisms of airway obstruction are not fully known but possibly involve the collapse of large airways at expiration, the bronchial wall thickening, retention of endobronchial secretion, and obliterative bronchitis. ${ }^{13,14}$ Interestingly, many patients with bronchiectasis may also show a concomitant restrictive defect. Some authors believe that the progressive bronchiectatic changes may be the cause of the mixed pulmonary function defect. ${ }^{15}$ Impaired pulmonary function is of prognostic importance in bronchiectasis. In these patients, Ip et $a^{16}$ showed that factors significantly associated with worse lung function were longer duration of disease, diffuse disease, older age, bronchial hyper-responsiveness, concomitant asthma, and more systemic inflammation. The degree of impaired pulmonary function in patients with bronchiectasis depends also on the associated clinical conditions, in particular tobacco smoking, which accelerates the obstructive damage and reduces the pulmonary function by approximately $15 \% .{ }^{17,18}$ Among the studies assessing pulmonary function in adults with bronchiectasis, many included a significant proportion of smokers, and some have not excluded the results of patients with a lung resection from the analysis. ${ }^{2}$

Although many studies sought to assess the factors associated with the deterioration of pulmonary function in individuals with bronchiectasis, ${ }^{19-23}$ none measured the isolated effect of its different causes. Therefore, the aim of the present study was to assess the impact of the various causes of bronchiectasis on clinical features, pulmonary function tests, and HRCT.

\section{Methods}

\section{Patients}

The present report was a cross-sectional study conducted with 179 consecutive patients recruited at the Newton Bethlem Medical Care Centre, Rio de Janeiro and the Pedro Ernesto University Hospital, Rio de Janeiro, Brazil, which are two referral centers that follow the majority of patients for many years. The study included individuals diagnosed with bronchiectasis based on the HRCT findings ${ }^{24}$ who were clinically stable (absence of respiratory infection in the 4 weeks preceding the study), had no history of smoking, and were $\geq 18$ years of age. Individuals with a history or diagnosis of asthma or a pleural or cardiovascular disease were excluded, as were the patients who had been subjected to a lung resection or used oral corticosteroids in the 4 weeks preceding the study. In addition, individuals for whom the cause of bronchiectasis could not be established or was doubtful and those with traction bronchiectasis secondary to an interstitial lung disease were excluded.
The participants were divided into five groups based on the etiology of bronchiectasis, as follows: sequelae of tuberculosis, history of non-tuberculosis infection, cystic fibrosis (CF), primary ciliary dyskinesia (PCD), and rheumatoid arthritis. The characterization of the etiology of bronchiectasis was based on chart review, where we seek to find certain criteria. Patients were diagnosed with pulmonary tuberculosis if Mycobacterium tuberculosis was isolated from their sputum or tissue specimens by mycobacterial culture. ${ }^{25}$ Etiology of bronchiectasis was attributed to non-tuberculosis infection if bacterial or viral infections were well documented in the medical records. ${ }^{26}$ The diagnosis of CF was based on at least two of the following criteria: sweat chloride concentration $>60 \mathrm{mEq} / \mathrm{mL}$, two clinical features consistent with $\mathrm{CF}$, or genetic testing demonstrating two mutations associated with CF. ${ }^{27}$ The diagnosis of PCD was made clinically and confirmed through transmission electron microscopy. ${ }^{28}$ The diagnosis of rheumatoid arthritis was made by a rheumatologist according to the American College of Rheumatology/European League Against Rheumatism collaborative initiative. ${ }^{29}$

The study was approved by the institutional research ethics committee. All participants provided informed consent.

\section{Clinical Data and Pulmonary Function Tests}

Clinical data were obtained through questionnaires and medical records. Dyspnea was assessed by means of the modified Medical Research Council (MRC) scale. ${ }^{30}$ Hemoptysis was defined as bleeding originating from the lower respiratory tract ${ }^{31}$ experienced at any time after the patient was diagnosed with bronchiectasis. Severity of hemoptysis was recorded if the hemoptysis led to hospitalization or required medical intervention beyond antibiotic therapy.

Spirometry, whole-body plethysmography, and measurement of the diffusing capacity for carbon monoxide (DLco) were performed using the computerized Collins Plus Pulmonary Function Testing Systems (Warren E. Collins, Inc., Braintree, MA, USA). To evaluate the bronchodilator response, the use of short-acting inhaled bronchodilators and long-acting inhaled bronchodilators before the test for 4 hours and 12 hours, respectively, was not allowed. ${ }^{31}$ All tests followed the standards formulated by the American Thoracic Society (ATS). ${ }^{32}$ The forced vital capacity (FVC), forced expiratory volume in 1 second $\left(\mathrm{FEV}_{1}\right)$, peak expiratory flow (PEF), mean expiratory flow between $25 \%$ and $75 \%$ of $\mathrm{FVC}$ $\left(\mathrm{FEF}_{25-75 \%}\right)$, total lung capacity (TLC), residual volume (RV), and DLco were measured. Bronchodilator response was identified based on the presence of a variation of $12 \%$ and $200 \mathrm{~mL}$ in $\mathrm{FEV}_{1}$ or FVC after the use of $400 \mu \mathrm{g}$ of inhaled albuterol. ${ }^{32}$ Pereira's (spirometry) and Neder's (static lung volumes and DLco) equations were used in the interpretation of the functional parameters. ${ }^{33,34}$ Airflow obstruction was defined by an $\mathrm{FEV}_{1} / \mathrm{FVC}$ value $<70 \%$ of predicted. A restrictive pattern was defined as the presence of a TLC $<$ $80 \%$ of predicted; this cutoff point was also used to define abnormality in DLco. ${ }^{32,35}$ 
Table 1. Anthropometry, clinical data, high-resolution computed tomography, and data on the pulmonary function of the investigated sample $(n=112)$.

\begin{tabular}{|c|c|}
\hline Variables & Values \\
\hline Sex (female/male) & $75 / 37$ \\
\hline Age (years) & $48.1 \pm 19.5^{\star}$ \\
\hline BMI $\left(\mathrm{kg} / \mathrm{m}^{2}\right)$ & $24.1 \pm 4.22^{*}$ \\
\hline Duration of symptoms (years) & $17.3 \pm 8.21^{\star}$ \\
\hline History of hemoptysis (\%) & 31.2 \\
\hline Dyspnea (MRC) & $1.87 \pm 0.92^{\star}$ \\
\hline HRCT score & $5.13 \pm 1.86^{\star}$ \\
\hline FVC (\% predicted) & $77.1 \pm 19.8^{\star}$ \\
\hline $\mathrm{FEV}_{1}(\%$ predicted $)$ & $62.1 \pm 24.8^{\star}$ \\
\hline FEV $/$ /FVC (\% predicted) & $64.8 \pm 12.8^{\star}$ \\
\hline PEF (\% predicted) & $67.5 \pm 28.8^{\star}$ \\
\hline $\mathrm{FEF}_{25-75 \%}(\%$ predicted $)$ & $42.6 \pm 21.4^{\star}$ \\
\hline TLC (\% predicted) & $93.7 \pm 20.8^{\star}$ \\
\hline $\mathrm{RV}$ (\% predicted) & $131.6 \pm 23.5^{\star}$ \\
\hline RV/TLC (\% predicted) & $45.9 \pm 12.1^{\star}$ \\
\hline DLco (\% predicted) & $79.9 \pm 13.8^{\star}$ \\
\hline
\end{tabular}

${ }^{*}$ Results expressed as mean \pm standard deviation.

$\mathrm{BMI}$, body mass index; MRC, Medical Research Council dyspnea scale, HRCT: high-resolution computed tomography; FVC, forced vital capacity; $\mathrm{FEV}_{1}$, forced expiratory volume in 1 second; PEF, peak expiratory flow; $\mathrm{FEF}_{25-75 \%}$, mean expiratory flow between $25 \%$ and $75 \%$ of FVC; TLC, total lung capacity; RV, residual volume; DLco, diffusing capacity for carbon monoxide.

\section{High-Resolution Computed Tomography}

The computed tomography (CT) images were recorded in a helical CT scanner with 64 channels (Brilliance 40, Philips Medical Systems, Cleveland, OH, USA). The readout time was set to 4 seconds, with an X-ray tube current of $458 \mathrm{~mA}$ and voltage of $120 \mathrm{kVp}$. Each image acquisition consisted of a block with 250 to 400 2-mm-thick cross sections separated by $1 \mathrm{~mm}$. The images were represented by a square matrix of 768 rows and 768 columns and were recorded without gantry tilt. For all subjects, end-inspiratory scans were obtained. An iodinated contrast agent was not used in any of the examinations. The extent of bronchiectasis was established by the modified scale described by Bhalla et $\mathrm{al}^{36}$, which ranges from 0 to 18 . Each lung lobe (considering the lingual and middle lobe as independent) was scored as follows: $0=$ no bronchiectasis; 1 = one or partial bronchopulmonary segment involved; 2 = two or more bronchopulmonary segments involved; and 3 = generalized cystic bronchiectasis. The HRCT scans were interpreted simultaneously by two radiologists who were blinded to the patients' data. The final decision was made by consensus.

\section{Data Analysis}

Quantitative data were expressed as the mean and standard deviation. Categorical variables were described using the relative values and expressed as a percentage. Comparisons of the anthropometry, clinical data, high-resolution CT, and pulmonary function tests according to the different causes of bronchiectasis were examined using the analysis of variance (ANOVA) followed by Bonferroni's post-hoc test. The frequencies between those individuals who had or did not have a history of hemoptysis were compared using the chisquared test. Pearson correlation coefficient was calculated to investigate the association between pulmonary function and HRCT score. A multifactorial variance analysis was performed to investigate the association between pulmonary function, different etiologies of bronchiectasis, and the possible confounders. This analysis allowed the inclusion of predictor variables (covariates) and allowed assessment of the impact of multiple covariates in the same model. This model was designed to analyze the $\mathrm{FEV}_{1}$ or DLco as the dependent variable with covariates of body mass index (BMI), history of hemoptysis (yes/no), duration of symptoms, dyspnea, HRCT score, and different causes of bronchiectasis. The analyses were performed using SigmaStat for Windows, version 3.5 (Systat Software, Inc., Chicago, IL, USA). Statistical significance was established as $P<0.05$.

\section{Results}

Each subject was tested with a maximum interval of one week. The evaluation was performed consecutively and in the following sequence: clinical, HRCT, and pulmonary function tests.

A total of 179 non-smokers who were diagnosed with bronchiectasis were assessed. Of these, 67 were excluded due to the following reasons: cause of bronchiectasis not established or questionable (35), history of asthma (18), bronchiectasis associated with interstitial lung disease (10), and history of lung resection (4). Of the 112 individuals who were included in the study, 34 had sequelae of tuberculosis, 29 had a history of non-tuberculosis infections, 21 had CF, 11 had PCD, and 17 had rheumatoid arthritis.

The anthropometric and clinical data, HRCT findings, and pulmonary function tests results corresponding to the full sample are described in table 1. Most participants were female $(66.9 \%)$, and the average age of the participants was $48.1 \pm 19.5$ years. The pulmonary function was normal in $28.6 \%$ of the volunteers; however, $48.2 \%$ exhibited obstructive defect, $7.1 \%$ had a restrictive defect, and $16.1 \%$ showed a mixed pattern. The DLco was normal in $52.7 \%$ of the sample and was reduced in $47.3 \%$.

Table 2 describes the anthropometric and clinical data and the HRCT findings distributed per group. Patients with CF exhibited the lowest average BMI $\left(20.6 \pm 3.71 \mathrm{~kg} / \mathrm{m}^{2}\right)$ and average age (25.2 \pm 6.05 years old). Among 21 patients with $\mathrm{CF}$, all had at least one sweat chloride concentration $>60$ $\mathrm{mEq} / \mathrm{mL}$, 9 were homozygous for $\Delta \mathrm{F} 508$, and $18 \mathrm{had}$ pancreatic insufficiency. In our sample of CF patients, 14 subjects were chronically infected by Pseudomonas aeruginosa, 5 were chronically infected by both $P$. aeruginosa and Burkholderia cepacia complex, and 6 patients had no 
Table 2. Anthropometry, clinical data, and high-resolution computed tomography according to the different etiologies of bronchiectasis.

\begin{tabular}{|c|c|c|c|c|c|c|}
\hline Variables & $\begin{array}{l}\text { Sequelae of } \\
\text { tuberculosis } \\
(n=34)\end{array}$ & $\begin{array}{l}\text { History of non- } \\
\text { tuberculosis } \\
\text { infection } \\
(n=29)\end{array}$ & $\begin{array}{l}\text { Cystic } \\
\text { fibrosis } \\
(n=21)\end{array}$ & $\begin{array}{l}\text { Primary } \\
\text { ciliary } \\
\text { dyskinesia } \\
(n=11)\end{array}$ & $\begin{array}{l}\text { Rheumatoid } \\
\text { arthritis } \\
(n=17)\end{array}$ & $P$ value \\
\hline Age (years) & $50.5 \pm 18.3^{*}$ & $60.8 \pm 16.3^{\star}$ & $25.2 \pm 6.05$ & $56 \pm 18.7^{*}$ & $50.4 \pm 16.3^{*}$ & $<0.001$ \\
\hline BMI $\left(\mathrm{kg} / \mathrm{m}^{2}\right)$ & $21.3 \pm 4.15^{\dagger}$ & $27.9 \pm 5.11$ & $20.6 \pm 3.71^{\dagger}$ & $24.7 \pm 3.98$ & $25.1 \pm 4.02$ & 0.002 \\
\hline History of hemoptysis (\%) & 58.8 & $24.1^{\ddagger \S}$ & 66.7 & $27.3^{\ddagger \S}$ & $23.5^{\ddagger \S}$ & 0.001 \\
\hline Use of inhaled bronchodilator (\%) & 50 & 55.2 & 95.2 & 81.8 & 64.7 & 0.22 \\
\hline Use of inhaled corticosteroids (\%) & $11.8^{\star}$ & $10.3^{*}$ & 85.7 & 72.7 & 64.7 & 0.02 \\
\hline Use of inhaled antibiotic (\%) & - & - & 76.2 & - & - & \\
\hline $\begin{array}{l}\text { Use of aerosolized recombinant } \\
\text { human DNase (\%) }\end{array}$ & - & - & 71.4 & - & - & \\
\hline
\end{tabular}

BMI, body mass index; MRC, Medical Research Council dyspnea scale; HRCT, high-resolution computed tomography. $P$ value $<0.005$ compared to patients with cystic fibrosis by using the Bonferroni multiple-correction test. ${ }^{\dagger} P$ value $<0.005$ compared to patients with history of non-tuberculosis infection by using the Bonferroni multiple-correction test. ${ }^{\ddagger} P$ value $<0.05$ compared to patients with sequelae of tuberculosis. ${ }^{\S} P$ value $<0.05$ compared to patients with cystic fibrosis.

Values in bold refer to significant differences.

chronic pulmonary infection. Hemoptysis was frequently found among the participants with CF (66.7\% of the cases) and those with sequelae of tuberculosis (58.8\% of cases). A hemoptysis that led to hospitalization or required medical intervention beyond antibiotic therapy was reported in 8 patients with sequelae of tuberculosis and 4 subjects with $\mathrm{CF}$. The highest HRCT score was exhibited in patients with $\mathrm{CF}$ $(6.03 \pm 1.03)$.

Table 3 describes the results of the pulmonary function in five groups. The lowest values of FVC $(66.8 \pm 16.8 \%), \mathrm{FEV}_{1}$
$(52.2 \pm 17.7 \%)$, TLC $(78.9 \pm 16.4 \%)$, and DLco $(74.1 \pm 15.2 \%)$ were exhibited in patients with sequelae of tuberculosis. Increases in RV were more accentuated in patients with $\mathrm{CF}$ (193.5 $\pm 39.5 \%)$ and PCD (189 $\pm 36.4 \%)$.

All variables were assessed in a multifactorial variance model (table 4). The covariates having significant associations with $\mathrm{FEV}_{1}$ were the etiology of bronchiectasis, HRCT score, and dyspnea (figures 1 and 2). In this model, the etiology of bronchiectasis, HRCT score, dyspnea, and history of hemoptysis were associated with the DLco.

Table 3. Pulmonary function tests according to the different etiologies of bronchiectasis.

\begin{tabular}{|c|c|c|c|c|c|c|}
\hline Variables & $\begin{array}{l}\text { Sequelae of } \\
\text { tuberculosis } \\
(n=34)\end{array}$ & $\begin{array}{l}\text { History of non- } \\
\text { tuberculosis } \\
\text { infection } \\
(n=29)\end{array}$ & $\begin{array}{l}\text { Cystic } \\
\text { fibrosis } \\
(n=21)\end{array}$ & $\begin{array}{l}\text { Primary } \\
\text { ciliary } \\
\text { dyskinesia } \\
(n=11)\end{array}$ & $\begin{array}{l}\text { Rheumatoid } \\
\text { arthritis } \\
(n=17)\end{array}$ & $P$ value \\
\hline FVC (\% predicted) & $66.8 \pm 16.8^{\star}$ & $93.3 \pm 16.1$ & $74.6 \pm 24.6^{*}$ & $79.5 \pm 19.8$ & $71.3 \pm 17.8^{\star}$ & $<0.001$ \\
\hline $\mathrm{FEV}_{1}(\%$ predicted) & $52.2 \pm 17.7^{\star}$ & $81.4 \pm 22.4$ & $57.3 \pm 26^{*}$ & $58.8 \pm 24.3$ & $56.3 \pm 23.7^{*}$ & $<0.001$ \\
\hline $\mathrm{FEV}_{1} / \mathrm{FVC}(\%$ predicted) & $63.9 \pm 13.7$ & $69.9 \pm 12.2$ & $63.8 \pm 14.8$ & $60.0 \pm 13.8$ & $63.9 \pm 14.7$ & 0.25 \\
\hline PEF (\% predicted) & $55.2 \pm 23.2^{*}$ & $82.7 \pm 32.1$ & $76.4 \pm 26.8$ & $64.5 \pm 31.4$ & $56.9 \pm 18.4$ & $<0.001$ \\
\hline $\mathrm{FEF}_{25-75 \%}(\%$ predicted $)$ & $32.6 \pm 19.9^{\star}$ & $62.9 \pm 25.9$ & $36.6 \pm 25.1^{*}$ & $29.5 \pm 21.7^{*}$ & $42.1 \pm 19.4$ & 0.002 \\
\hline TLC (\% predicted) & $78.9 \pm 16.4^{\dagger \ddagger}$ & $97.9 \pm 10.3^{\S}$ & $107.5 \pm 24.2$ & $114.3 \pm 23.2$ & $85.2 \pm 12.4^{\dagger \ddagger}$ & $<0.001$ \\
\hline RV (\% predicted) & $101.1 \pm 22.1^{\dagger \ddagger}$ & $112 \pm 19.2^{\dagger \ddagger}$ & $193.5 \pm 39.5$ & $189 \pm 36.4 \%$ & $106.2 \pm 30.2^{\dagger \ddagger}$ & $<0.001$ \\
\hline RV/TLC (\% predicted) & $38.2 \pm 8.45^{\dagger}$ & $42.6 \pm 7.98$ & $45.6 \pm 17$ & $56.1 \pm 10.6$ & $36.5 \pm 10.7^{\dagger}$ & 0.02 \\
\hline DLco (\% predicted) & $74.1 \pm 15.2$ & $92.4 \pm 12^{\S}$ & $76 \pm 9.6$ & $88.2 \pm 10.3$ & $75.3 \pm 13.9$ & 0.01 \\
\hline Bronchodilator response (\%) & 11.8 & 13.8 & 19 & 18.2 & 11.8 & 0.19 \\
\hline
\end{tabular}

FVC, forced vital capacity; FEV , forced expiratory volume in 1 second; PEF, peak expiratory flow; FEF TLC, total lung capacity; RV, residual volume; DLco, diffusing capacity for carbon monoxide. * $P$ value $<0.005$ compared to patients with history of non-tuberculosis infection by using the Bonferroni multiple-correction test. ${ }^{\dagger} P$ value $<0.005$ compared to patients with primary ciliary dyskinesia by using the Bonferroni multiplecorrection test. $¥ P$ value $<0.005$ compared to patients with cystic fibrosis by using the Bonferroni multiple-correction test. $\$ P$ value $<0.005$ compared to patients with sequelae of tuberculosis by using the Bonferroni multiple-correction test.

Values in bold refer to significant differences. 


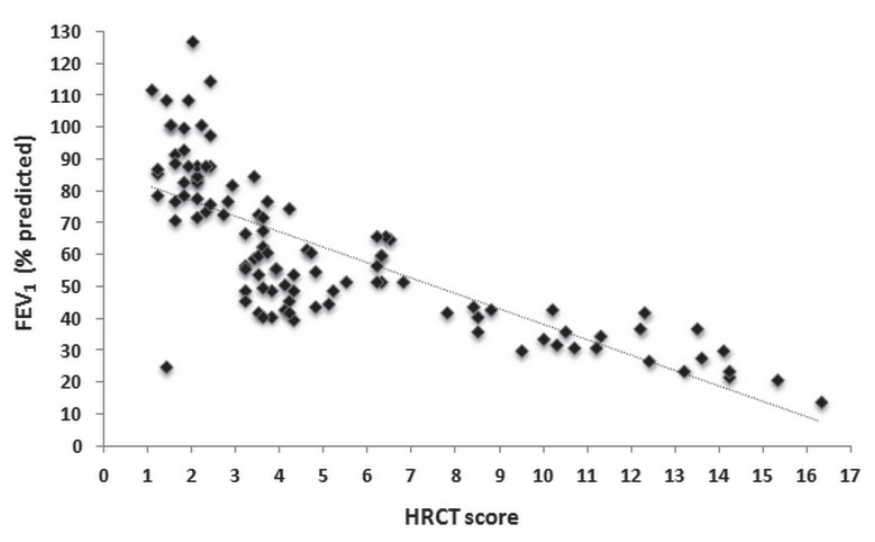

Figure 1. Relationship between the forced expiratory volume in 1 second $\left(F E V_{1}\right)$ and the high-resolution computed tomography (HRCT) score $(r=-0.77 ; P<0.0001)$.

\section{Discussion}

The main findings of the present study were the following: (a) among adults with bronchiectasis, the presence of hemoptysis, degree of dyspnea, and HRCT score vary as a function of the etiology of disease; and (b) the abnormal changes in the pulmonary function depend on the etiology of disease. To the best of our knowledge, no previous study focused on the impact of the various causes of bronchiectasis on the patients' clinical data, pulmonary function tests, and HRCT.

Most of the participants in the present study had a history of lung infection, which agrees with the reports in the literature and with the local epidemiological conditions relative to the occurrence of acute respiratory infections and pulmonary tuberculosis, with the corresponding bronchopulmonary sequelae. ${ }^{37}$ In Brazil, Bogossian et al ${ }^{8}$ studied 314 individuals with bronchiectasis and found that it manifests at around the fifth decade of life and mostly in females, which corresponded to $65 \%$ of that sample. Alternatively, Gomes Neto et $\mathrm{al}^{38}$ found that the disease affected the economically active population, that is, individuals who were 28 to 48 years of age. In the present study, the participants with CF exhibited a lower average age ( $25.2 \pm 6.05$ years old; $P<0.001)$, which is justified by the fact that $\mathrm{CF}$ is a genetic disorder attended by early lung affection. ${ }^{39}$

Because of the wide spread use of HRCT at the present time, bronchiectasis is being diagnosed more often and earlier than in the past..$^{23}$ Application of the modified Bhalla scale to the analysis of the extension of bronchiectasis by HRCT $^{36}$ resulted in an average score of $5.13 \pm 1.86$, which is higher than the one found by Martínez-García et $\mathrm{al}^{20}(4.40 \pm 0.27)$. This discrepancy might be accounted for by the inclusion of individuals with $\mathrm{CF}$ in our study, as that group exhibited the highest average score by the HRCT $(6.03 \pm 1.03)$.

Upon assessment of the pulmonary function of the participants, the most frequent pattern found corresponded to airflow

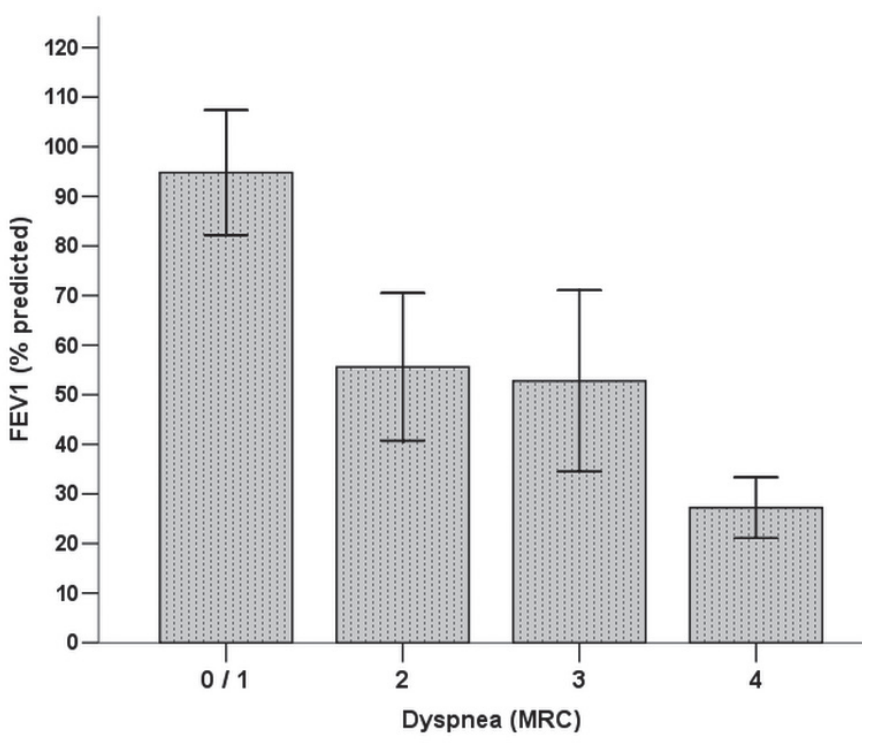

Figure 2. Mean and standard deviation of forced expiratory volume in 1 second $\left(\mathrm{FEV}_{1}\right)$ according to the modified Medical Research Council (MRC) scale. Significant difference $(P<0.0001)$ was found between the $\mathrm{FEV}_{1}$ and MRC scales (degree $0 / 1>$ degree 2 = degree $3>$ degree 4 ).

Table 4. Multifactorial variance analysis: relationship between the pulmonary function, clinical data, high-resolution computed tomography, and different etiologies of bronchiectasis of the studied subjects (only statistically significant associations are shown).

\begin{tabular}{|c|c|c|c|c|c|}
\hline \multirow[b]{2}{*}{ Outcome variable } & \multirow[b]{2}{*}{ Independent variables } & \multicolumn{3}{|c|}{ Unstandardized coefficient } & \multirow[b]{2}{*}{$P$ value } \\
\hline & & B & SE & Wald $F$ test & \\
\hline \multirow[t]{3}{*}{$\mathrm{FEV}_{1}$} & Etiology of bronchiectasis & 4.28 & 1.69 & 8.81 & 0.001 \\
\hline & HRCT score & 3.02 & 1.54 & 6.57 & 0.009 \\
\hline & Dyspnea & 2.33 & 1.32 & 4.93 & 0.029 \\
\hline \multirow[t]{4}{*}{ DLco } & Etiology of bronchiectasis & 4.41 & 1.82 & 9.01 & 0.001 \\
\hline & HRCT score & 3.28 & 1.74 & 7.82 & 0.008 \\
\hline & Dyspnea & 2.78 & 1.41 & 5.03 & 0.021 \\
\hline & History of hemoptysis & 2.43 & 1.37 & 4.95 & 0.032 \\
\hline
\end{tabular}

B, regression coefficient; SE, standard error; $\mathrm{FEV}_{1}$, forced expiratory volume in 1 second; HRCT, high-resolution computed tomography; DLco, diffusing capacity for carbon monoxide.

$16 \quad$ Bronchiectasis and pulmonary function tests

CM\&R 2015 : 1 (March) 
obstruction, ${ }^{2}$ as it was exhibited by $48.2 \%$ of the sample. The reduction of the DLco (that occurred in $47.3 \%$ of our sample) has been associated with more advanced stages of disease, which might possibly be a relevant characteristic of our sample. ${ }^{40}$ Similarly, Bogossian et $\mathrm{al}^{8}$ found lower $\mathrm{FEV}_{1}$ $(54.5 \pm 22.8 \%$ vs. $67.4 \pm 27.6 \%)$ and FVC $(70.4 \pm 22.2 \%$ vs. 81.8 $\pm 24.2 \%$ ) values in individuals with post-tuberculosis bronchiectasis compared to those without a history of tuberculosis. The greater reduction of $\mathrm{FEV}_{1}$ and $\mathrm{FVC}$ in individuals with post-tuberculosis bronchiectasis might be due to a greater severity and intensity of the bronchial and parenchymal damage; in addition, the reduced FVC might denote an airway obstruction by mucus or an airway collapse. ${ }^{18}$ Conversely, the course of bronchiectasis due to repetitive pneumonia is milder, with a low degree of underlying fibrosis, and is almost always located in the same lung area. These facts might at least partially account for the lesser impact of bronchiectasis on the pulmonary function tests of that particular group of individuals in the present study. It is worth noting the considerable degree of air trapping in patients with $\mathrm{CF}$ and PCD, which is compatible with the physiopathology of those conditions. ${ }^{41}$

We also investigated whether the clinical data, HRCT score, different causes of bronchiectasis, and anthropometric characteristics would demonstrate an independent role in predicting pulmonary function. In this investigation, the etiology of bronchiectasis, HRCT score, and dyspnea were covariates for both $\mathrm{FEV}_{1}$ and DLco. Roberts et $\mathrm{al}^{42}$ found that the reduction of $\mathrm{FEV}_{1}$ correlated with higher scores for the MRC dyspnea score and with the expansion of disease via HRCT. Interestingly, Zhou et $\mathrm{al}^{43}$ found that the prevalence of bronchiectasis in individuals age $\geq 40$ years bears correlation with several factors, including respiratory infections during childhood and tuberculosis. Using a multivariate regression model, Lee et $\mathrm{al}^{19}$ found that the HRCT score was the main independent predictor of $\mathrm{FEV}_{1}$. However, those authors excluded individuals with post-tuberculosis bronchiectasis from their sample. In a study with 91 patients, Loebinger et $\mathrm{al}^{44}$ found that a reduction of the DLco is a key indicator of the prognosis of mortality among individuals with bronchiectasis. According to those authors, in some individuals with bronchiectasis, the reduction of the DLco is due to pulmonary hypertension.

A critical analysis of the results and limitations of the present study is necessary. First, there are a small number of patients in each group. However, we used several exclusion criteria to assess more reliably the results of pulmonary function tests. Second, the inclusion of patients with bronchiectasis due to immunodeficiency or nontuberculous mycobacterial lung disease could allow a more accurate assessment of the impact of the causes of bronchiectasis on the variables studied. Third, the present report was a cross-sectional study including clinically stable patients. Future studies should approach the analysis of pulmonary function tests and HRCT findings relative to the long-term results and their role in acute exacerbations. Fourth, the volunteers were recruited at two centers, which might hinder the generalization of the results. Finally, the HRCT assessment was performed consensually by two radiologists, rather than by independent examiners. Nevertheless, we believe that this assessment was not significantly affected, as the radiologists were blinded to the remainder of the participants' data.

The strength of this study is that a relatively large number of subjects were evaluated in a systematic fashion. Moreover, this study assessed the impact of the various causes of bronchiectasis in a series of measurements that may have relevance for clinical interventions. A high frequency of severe hemoptysis in patients with post-tuberculosis bronchiectasis raises the possibility of more aggressive intervention to prevent bleeding. High HRCT scores and extensive air trapping in patients with PCD point out the need for clinical trials aiming at assessing the impact of mucolytic therapy in these patients.

To conclude, the results of the present study show that in adults with bronchiectasis, the abnormal changes in pulmonary function depend on the cause of the underlying disease and, to a lesser degree, on the HRCT score, degree of dyspnea, and history of hemoptysis. In addition, the individuals with posttuberculosis bronchiectasis exhibited lower values of $\mathrm{FEV}_{1}$, TLC, and DLco. The adults with CF and bronchiectasis exhibited higher HRCT scores and a greater degree of air trapping, as denoted by the RV values.

\section{Acknowledgements}

The authors wish to thank the Rio de Janeiro State Research Supporting Foundation (FAPERJ).

\section{References}

1. Goeminne P, Dupont L. Non-cystic fibrosis bronchiectasis: diagnosis and management in 21 st century. Postgrad Med J 2010;86:493-501.

2. Pasteur MC, Bilton D, Hill AT; British Thoracic Society Bronchiectasis non-CF Guideline Group. British Thoracic Society guideline for non-CF bronchiectasis. Thorax 2010;65:1-58.

3. Tsang KW, Chan K, Ho P, Zheng L, Ooi GC, Ho JC, Lam W. Sputum elastase in steady-state bronchiectasis. Chest 2000;117:420-426.

4. Barker AF, Bardana EJ Jr. Bronchiectasis: update of an orphan disease. Am Rev Respir Dis 1988;137:969-978.

5. Rademacher J, Welte T. Bronchiectasis--diagnosis and treatment. Dtsch Arztebl Int 2011;108:809-815.

6. Tsang KW, Tipoe GL. Bronchiectasis: not an orphan disease in the East. Int J Tuberc Lung Dis 2004;8:691-702.

7. Chan $\mathrm{CH}$, Ho AK, Chan RC, Cheung H, Cheng AF. Mycobacteria as a cause of infective exacerbation in bronchiectasis. Postgrad Med J 1992;68:896-899.

8. Bogossian M, Santoro IL, Jamnik S, Romaldini H. Bronchiectasis: a study of 314 cases tuberculosis x nontuberculosis. J Pneumol 1998;24:11-16.

9. O’Donnell AE. Bronchiectasis. Chest 2008;134:815-823.

10. Hansell DM. Bronchiectasis. Radiol Clin North Am 1998;36:107-128. 
11. Barker AF. Bronchiectasis. N Engl J Med 2002;246:1383-1393.

12. Martínez-García MA, Perpiñá-Tordera M, Román-Sánchez P, Soler-Cataluña JJ. Quality-of-life determinants in patients with clinically stable bronchiectasis. Chest 2005; 128:739-745.

13. Hansell DM, Wells AU, Rubens MB, Cole PJ. Bronchiectasis: functional significance of areas of decreased attenuation at expiratory CT. Radiology 1994;193:369-374.

14. Ip MS, So SY, Lam WK, Yam L, Liong E. High prevalence of asthma in patients with bronchiectasis in Hong Kong. Eur Respir J 1992;5:418-423.

15. Pande JN, Jain BP, Gupta RG, Guleria JS. Pulmonary ventilation and gas exchange in bronchiectasis. Thorax 1971;26:727-733.

16. Ip M, Lauder IJ, Wong WY, Lam WK, So SY. Multivariate analysis of factors affecting pulmonary function in bronchiectasis. Respiration 1993;60:45-50.

17. Ellis DA, Thornley PE, Wightman AJ, Walker M, Chalmers J, Crofton JW. Present outlook in bronchiectasis: clinical and social study and review of factors influencing prognosis. Thorax 1981:36:659-664.

18. Murray J, Nadel J. Texbook of respiratory medicine. 3rd ed. Philadelphia, PA: WB Saunders Company; 2000.

19. Lee JH, Kim YK, Kwag HJ, Chang JH. Relationships between high-resolution computed tomography, lung function and bacteriology in stable bronchiectasis. J Korean Med Sci 2004;19:62-68.

20. Martínez-García MA, Soler-Cataluña JJ, Perpiñá-Tordera M, Román-Sánchez P, Soriano J. Factors associated with lung function decline in adult patients with stable non-cystic fibrosis bronchiectasis. Chest 2007;132:1565-1572.

21. Martínez-García MA, Perpiña-Tordera M, Soler-Cataluña JJ, Román-Sánchez P, Lloris-Bayo A, González-Molina A. Dissociation of lung function, dyspnea ratings and pulmonary extension in bronchiectasis. Respir Med 2007; 101:2248-2253.

22. Alzeer AH. HRCT score in bronchiectasis: correlation with pulmonary function tests and pulmonary artery pressure. Ann Thorac Med 2008;3:82-86.

23. Habesoglu MA, Tercan F, Ozkan U, Fusan EO. Effect of radiological extent and severity of bronchiectasis on pulmonary function. Multidiscip Respir Med 2011; 6:284-290

24. Naidich DP, McCauley DI, Khouri NF, Stitik FP, Siegelman SS. Computed tomography of bronchiectasis. J Comput Assist Tomogr 1982;6:437-444.

25. Conde MB, Melo FA, Marques AM, Cardoso NC, Pinheiro VG, Dalcin Pde T, Machado Junior A, Lemos AC, Netto AR, Durovni B, Sant'Anna CC, Lima D, Capone D, Barreira D, Matos ED, Mello FC, David FC, Marsico G, Afiune JB, Silva JR, Jamal LF, Telles MA, Hirata MH, Dalcolmo MP, Rabahi MF, Cailleaux-Cesar M, Palaci M, Morrone N, Guerra RL, Dietze R, Miranda SS, Cavalcante SC, Nogueira SA, Nonato TS, Martire T, Galesi VM, Dettoni Vdo V; BTA Committee on Tuberculosis; BTA Guidelines on Tuberculosis Work Group. III Brazilian Thoracic Association Guidelines on tuberculosis. J Bras Pneumol 2009;35:1018-1048.

26. Cobanoglu U, Yalcinkaya I, Er M, Isik AF, Sayir F, Mergan D. Surgery for bronchiectasis: The effect of morphological types to prognosis. Ann Thorac Med 2011;6:25-32.

27. Farrell PM, Rosenstein BJ, White TB, Accurso FJ, Castellani C, Cutting GR, Durie PR, Legrys VA, Massie J, Parad RB, Rock MJ, Campbell PW 3rd; Cystic Fibrosis Foundation. Guidelines for diagnosis of cystic fibrosis in newborns through older adults: Cystic Fibrosis Consensus Report. J Pediatr 2008;153:S4-S14.
28. Bush A, Cole P, Hariri M, Mackay I, Phillips G, O'Callaghan C, Wilson R, Warner JO. Primary ciliary dyskinesia: diagnosis and standards of care. Eur Respir J 1998;12:982-988.

29. Aletaha D, Neogi T, Silman AJ, Funovits J, Felson DT, Bingham CO 3rd, Birnbaum NS, Burmester GR, Bykerk VP, Cohen MD, Combe B, Costenbader KH, Dougados M, Emery P, Ferraccioli G, Hazes JM, Hobbs K, Huizinga TW, Kavanaugh A, Kay J, Kvien TK, Laing T, Mease P, Ménard HA, Moreland LW, Naden RL, Pincus T, Smolen JS, Stanislawska-Biernat E, Symmons D, Tak PP, Upchurch KS, Vencovsky J, Wolfe F, Hawker G. 2010 rheumatoid arthritis classification criteria: an American College of Rheumatology/European League Against Rheumatism collaborative initiative. Ann Rheum Dis 2010;69:1580-1588.

30. Mahler DA, Weinberg DM, Wells CK, Feinstein AR. The measurement of dyspnea. Contents, interobserver agreement, and physiologic correlates of two new clinical indexes. Chest 1984;85:751-758.

31. Hirshberg B, Biran I, Glazer M, Kramer MR. Hemoptysis: etiology, evaluation, and outcome in a tertiary referral hospital. Chest 1997;112:440-444.

32. Miller MR, Hankinson J, Brusasco V, Burgos F, Casaburi R, Coates A, Crapo R, Enright P, van der Grinten CP, Gustafsson P, Jensen R, Johnson DC, MacIntyre N, McKay R, Navajas D, Pedersen OF, Pellegrino R, Viegi G, Wanger J; ATS/ERS Task Force. ATS/ERS Task Force. Standardisation of spirometry. Eur Respir J 2005;26:319-338.

33. Pereira CA, Sato T, Rodrigues SC. New reference values for forced spirometry in white adults in Brazil. J Bras Pneumol 2007;33:397-406.

34. Neder JA, Andreoni S, Castelo-Filho A, Nery LE. Reference values for lung function tests. I. Static volumes. Braz J Med Biol Res 1999;32:703-717.

35. Habesoglu MA, Ugurlu AO, Eyuboglu FO. Clinical, radiologic, and functional evaluation of 304 patients with bronchiectasis. Ann Thorac Med 2011;6:131-136.

36. Bhalla M, Turcios N, Aponte V, Jenkins M, Leitman BS, McCauley DI, Naidich DP. Cystic fibrosis: scoring system with thin-section CT. Radiology 1991;179:783-788.

37. Moreira JS, Porto NS, Camargo JJP, Felicetti JC, Cardoso PFG, Moreira ALS, Andrade CF. Bronchiectasis: diagnostic and therapeutic features: a study of 170 patients. J Pneumol 2003;29:258-263.

38. Gomes Neto A, Medeiros ML, Gifoni JMM. Localized and multisegmental bronchiectasis: clinical-epidemiological profile and surgical treatment results in 67 cases. J Pneumol 2001;27:1-6.

39. Lopes AJ, Mafort TT, Sá Ferreira A, Santos de Castro MC, Cássia de Firmida M, de Andrade Marques E. Is the type of chronic pulmonary infection a determinant of lung function outcomes in adult patients with cystic fibrosis? Monaldi Arch Chest Dis 2012;77:3-4:122-128.

40. Koulouris NG, Retsou S, Kosmas E, Dimakou K, Malagari K, Mantzikopoulos G, Koutsoukou A, Milic-Emili J, Jordanoglou J. Tidal expiratory flow limitation, dyspnea and exercise capacity in patients with bilateral bronchiectasis. Eur Respir J 2003;21:743-748.

41. Penafortes JT, Guimarães FS, Moço VJ, Almeida VP, Dias RF, Lopes AJ. Association among posture, lung function and functional capacity in cystic fibrosis. Rev Port Pneumol 2013;19:1-6.

42. Roberts HR, Wells AU, Milne DG, Rubens M, Kolbe J, Cole P, Hansell DM. Airflow obstruction in bronchiectasis: correlation between computed tomography features and pulmonary function tests. Thorax 2000;55:198-204. 
43. Zhou YM, Wang C, Yao WZ, Chen P, Kang J, Huang SG, Chen BY, Wang CZ, Ni DT, Liu SM, Wang XP, Wang DL, Lü JC, Zheng JP, Zhong NS, Ran PX. The prevalence and risk factors of bronchiectasis in residents aged 40 years old and above in seven cities in China. Zhonghua Nei Ke Za Zhi 2013;52:379-382.

44. Loebinger MR, Wells AU, Hansell DM, Chinyanganya N, Devaraj A, Meister M. Mortality in bronchiectasis: a longterm study assessing the factors influencing survival. Eur Respir J 2009;34:843-849.

\section{Author Affiliations}

Agnaldo José Lopes, PhD ${ }^{*,}$; Gustavo Bittencourt Camilo, MSc ; Sara Lucia Silveira de Menezes, PhD ; and Fernando Silva Guimarães, $P h D^{\prime}$

*Laboratory of Respiratory Physiology, State University of Rio de Janeiro, Brazil

'Rehabilitation Sciences Master's Program, Augusto Motta University Center, Rio de Janeiro, Brazil

Department of Radiology, State University of Rio de Janeiro, Rio de Janeiro, Brazil 